\title{
Potential of Seriales, Flacourtia jangomas (Lour.) Raeusch, fruit for wine production
}

Lynette C. Cimafranca" and Erlinda I. Dizon ${ }^{2}$

\begin{abstract}
Flacourtia jangomas, locally known as seriales, is one of the indigenous tree species in the island of Leyte, Philippines that is neglected and underutilized. To maximize its utilization, the potential of the commodity for wine-making was explored using the Placket-Burman (PB) experiment, which was carried out to identify the most significant factors affecting the quality of the wine. There were seven variables $(n=7)$ identified, namely; fermentation temperature, contact time, sugar level, dilution, microbial strain and two dummy variables with a total of eight runs. Results show that fermentation temperature, contact time, sugar level and microbial culture significantly affected the sensory quality of seriales wine.
\end{abstract}

Keywords: Seriales, Flacourtia jangomas, Plackett-Burman Design, Wine

\section{INTRODUCTION}

Flacourtia jangomas (Lour.) Raeusch, locally known as seriales is a less known and an underutilized plant in the Philippines. Parvin et al (2011) reported that seriales contains an array of compounds such as terpenoids, alkaloids, flavonoids and tannins, lignans and flavanolignans, glucosides, coumarins, isocoumarins, xanthones, quinones, limonoids and phenazines that make it important in traditional medicine (Singh \& Singh 2010). Furthermore, Kermasha et al (1987) reported that it also contains proteins, vitamin $C$, fructose, $a, \beta$ glucose, sucrose, calcium, potassium, phosphorus, iron, and magnesium. With such beneficial components, utilization of seriales can be maximized by developing a high-value product such as wine. Hence, this study was done, firstly, to assess the potential of the seriales fruit for wine production, and secondly, to determine the effects of different factors or variables on the sensory quality of the resulting wine. Results of the study may pave the way for the development of other high-value products from the fruit, and for the conservation of this important native Philippine species.

\footnotetext{
'Visayas State University, Visca, Baybay City, Leyte

${ }^{2}$ Institute of Food Science and Technology, College of Agriculture and Food Science, University of the Philippines Los Baños, 4031, College Laguna
}

* Corresponding Author. Address: Visayas State University, Visca, Baybay City, Leyte; Email:lynette. cimafranca@vsu.edu.ph DOI: $10.32945 /$ atr 4026.2018 


\section{MATERIALS AND METHODS}

The preliminary study was done to screen variables that affect product formulation and processing of seriales wine using the Plackett-Burman design. Table 1 shows the variables assigned with high (+) and low (-) values, which were laid out in a design matrix presented in Table 2. The seriales wine was produced following the method of Dizon (2009) (as cited by Belina-Aldemita 2013), with slight modification depending on the factor and level indicated in the 8-run PB design matrix (Table 2).

A sensory quality evaluation was conducted on eight wine sample treatments produced with sensory acceptability as response variables, by 32 Bachelor of Science in Food Technology students of the Visayas State University. The 9-point Hedonic Rating Scale was used. Results were decoded, and sensory acceptability was analyzed using the SAS software. The principal effects of each variable on the sensory acceptability were estimated as the difference between both averages of measurements made at the higher level and the lower level. The significance of each variable was determined.

Table 1. Range of values for the different variables used in the Placket-Burman screening experiment for seriales wine

\begin{tabular}{lcc}
\hline \multicolumn{1}{c}{ Independent Variables } & Low $(-)$ & Range of Values \\
& & High $(+)$ \\
Fermentation temperature $\left({ }^{\circ} \mathrm{C}\right)$ & 15 & 35 \\
Skin \& Seed Contact time & - & + \\
Sugar level (TSS) & $15^{\circ} \mathrm{B}$ & $25^{\circ} \mathrm{B}$ \\
Dilution & $1: 2$ & $1: 4$ \\
Microbial strain & Saccharomyces ellipsoideus & Saccharomyces bayanus \\
Dummy 1 & - & + \\
Dummy 2 & - & + \\
\hline
\end{tabular}

Table 2. Plackett-Burman experimental design (8-run matrix) for screening of processing conditions affecting sensory quality of seriales wine

\begin{tabular}{cccccccc}
\hline \multirow{2}{*}{ Runs } & $\mathrm{V}_{1}$ & $\mathrm{~V}_{2}$ & $\mathrm{~V}_{3}$ & $\mathrm{~V}_{4}$ & $\mathrm{~V}_{5}$ & $\mathrm{~V}_{6}$ & $\mathrm{~V}_{7}$ \\
\hline 1 & + & - & - & + & - & + & + \\
2 & + & + & - & - & + & - & + \\
3 & + & + & + & - & - & + & - \\
4 & - & + & + & + & - & - & + \\
5 & + & - & + & + & + & - & - \\
6 & - & + & - & + & + & + & - \\
7 & - & - & + & - & + & + & + \\
8 & - & - & - & - & - & - & - \\
\hline
\end{tabular}


wine production: a preliminary study

\section{RESULTS AND DISCUSSION}

\section{Effect of Temperature}

As shown in Table 3, the independent variables, namely; fermentation temperature, contact time and sugar level, had significant negative effects on color acceptability. The color of seriales wine produced at lower temperature $\left(15^{\circ} \mathrm{C}\right)$ was more preferred than those produced at higher temperature. The color of the wine was principally due to the anthocyanin content of the fruit as well as its derivatives formed during the vinification process (Busse-Valverde et al 2011, Mazza \& Francis, 1995 as cited by $\mathrm{He}$ et al 2012). These compounds are basically affected by temperature (Fennema 1996). According to Buglas (2011) and Ough (1992), temperature of fermentation has also a considerable effect on product color. This is because anthocyanin degradation is greater with an increase in temperature (Laleh et al 2006), which consequently affects product color and ultimately the respondents' perception of the product. This study clearly revealed that color acceptability was high at low temperatures.

\section{Effect of Contact Time}

Aside from temperature, fruit skin and seed contact time (time when the seeds and skin were in contact with the fermenting must) had a significant negative effect to all response variables except aroma acceptability. In a recent study of Cimafranca (2017), it was found that tannins (146.80mg VE. $100 \mathrm{~g}^{-1}$ )and anthocyanins ( $306.69 \mathrm{mg} \mathrm{GCE} \cdot 100 \mathrm{~g}^{-1}$ ) were high in seriales, with the bulk of these compounds present in the seeds and skin. Higher concentration of these compounds are extracted with longer contact time. When mixed into the wine must, these compounds significantly decreased the acceptability perception of color, taste, flavor, alcohol and general acceptability. This means that reducing contact time may increase acceptability ratings of the aforementioned variables.

The pericarp or "skin" of the fruit primarily contributes to the appealing color of a fruit. The pericarp contains anthocyanins which impart color, as well as phenolics (Reynolds 2010). Previous reports stated that skin contact to the must, increase the levels of phenolics, which impart color, as well as other physiological properties, and improved the sensory characteristics of white wine made from Vitis vinifera (Darias-Martin et al 2000, Gomez-Plaza et al 2001). However, the results in seriales wine showed otherwise. Every unit increase in the time of contact of skin and seed in the must during fermentation resulted in decreased color acceptability by 0.752 (Table 3), suggesting that skin and seed contact time should be lowered. Extended skin contact can result to decrease in total anthocyanins and greater extraction of other phenolic compounds (Darias-Martin et al 2000, Sipiora \& Granda 1998) resulting to undesirable browning of the product. In the study of Sims and Morris (1986), wherein the commercial tannin incorporated into Red Muscadine (Vitis rotundifolia) wine did not affect color intensity of the product, but slightly increased browning. Also, non-enzymatic changes leading to browning involving polyphenols is another aspect that must be considered. According to Matthew Mayer and Harel (1979), Parpia (1971) and Vamos-Vigyazo (1981) as cited by Cheng and Crisosto (1981), different aspects of food browning may be attributable to polyphenol 
Cimafranca \& Dizon

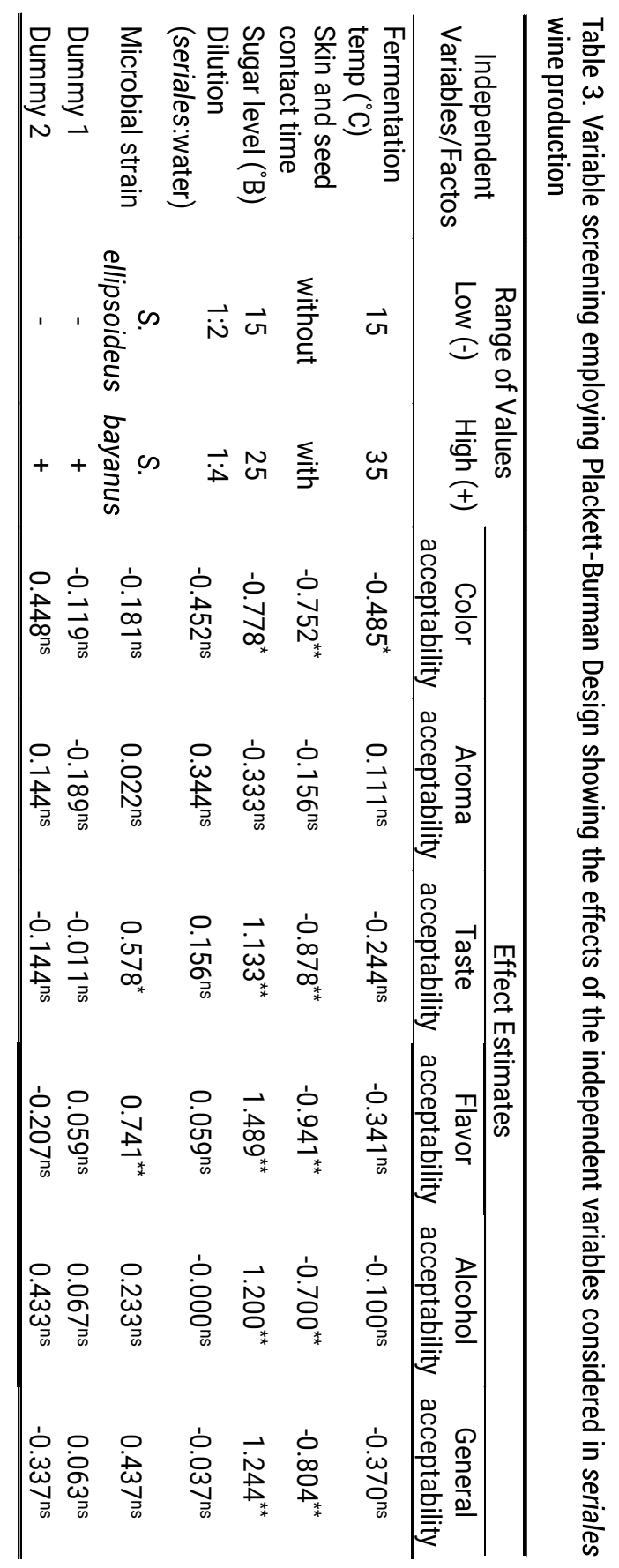


wine production: a preliminary study

reaction. Tannin is an important polyphenol. Although tannin is responsible for the astringent character of wine, it also acts as color stabilizer. Hence, it is necessary to extract it together with the anthocyanin, but the fraction of tannin with respect to the content anthocyanins should also be taken into account since duration of contact time affects anthocyanin and tannin extraction. According to Kennedy and Peynot des Gachons (2003), the maximum amount of color that could be extracted was roughly $50 \%$ of what was available, and a balanced wine was achieved when only $15 \%$ of tannin was extracted. Furthermore, they observed that tannin extracted slowly than anthocyanin. They found that anthocyanin diffused rapidly in wine during the early stage of fermentation, while an increase in tannin content was observed as fermentation progressed. Thus, increasing the contact time favors more extraction of tannin, compromising the balance between both compounds, resulting to unstable wine color.

Skin and contact time has been reported to affect extraction of aroma compounds (Schmidtz \& Noble 1983). This experiment revealed that duration of skin and contact time to the fermenting must had no significant effect on aroma acceptability. This is corroborated by the findings of Ribereau-Gayon et al (2006), that the effect of aroma on varietal wine is much less clear. Increased contact time of skin similar to aroma may contribute to increase astringency of the wine, which probably affects the taste acceptability of the product. This was observed by Aleixandre-Tudo et al (2015) in the production of South African Chenin Blanc White Wine.

\section{Effect of Sugar Content}

Sugar content is one of the major contributing factors to the taste, flavor, alcohol and general acceptability of the seriales wine. There was a positive response of the aforementioned dependent variables with increase in sugar level. The findings of Malundo et al (2001) and Rossiter et al (2000) is in agreement with this result in seriales. These authors found that increasing sugar level also increases the flavor acceptability of kiwi and mango wine, respectively. However, in apple vermouth (Joshi \& Sandhu 2000) and Hunter Valley Semillon wine (Blackman et al 2010), lower sugar concentration was most preferred. In terms of alcohol acceptability, Soufleros et al (2001) found that sugar level significantly influenced alcohol acceptability. This corroborates with the findings of this study that sugar level had a significantly positive effect $(+1.200)$ on alcohol acceptability, which means the higher the sugar level (Table 3), the higher is the alcohol acceptability.

\section{Effect of Yeast Strain}

The yeast strain Saccharomyces bayanus used in the fermentation process enhanced the taste and flavor acceptability of the seriales wine. King et al (2010) reported that the microbial inoculum used in the production of Sauvignon Blanc wine affected consumer acceptance, specifically on aroma or flavor attribute, and are thought of as driving the differences in consumer preferences. This could be due to the effect of the activity of these microorganisms in the chemical composition of the wine. In the study of Eglinton et al (2000), wine fermented with $S$. bayanus contained more succinic acid, glycerol, acetaldehyde and $\mathrm{SO}_{2}$, and less of acetic acid, malic acid and ethyl acetate in comparison with wine made from 
Saccharomyces cerevisiae. Volatile compound formation and concentration in mango wine was also reported by Reddy and Reddy (2009) to be dependent on the S. cerevisiae strain used.

\section{CONCLUSION}

Seriales fruit has a big potential for processing into a high-value product such as wine. Among the different independent factors that affect quality of the wine, the most significant and critical ones are fermentation temperature, contact time, sugar level and the kind of yeast strain used.

\section{ACKNOWLEDGMENT}

The researchers would like to express their gratitude to DOST-ASTHRDP for the financial assistance and the University of the Philippines Los Baños, Visayas State University-Department of Food Science and Technology and the people of the A and A Circuit for the help that made this study possible.

\section{REFERENCES}

Aleixandre-Tudo JL, Weightman C, Panzeri V, Nieuwoudt HH \& du Toit WJ. 2015. Effect of skin contact before and during alcoholic fermentation on the chemical and sensory profile of South African Chenin Blanc White Wines. South African Journal for Enology and Viticulture, 36(3):366-377

Belina-Aldemita MA, Sabularse VC, Dizon El, Hurtada WA \& Torio MO. 2013. Physicochemical properties of bignay [Antidesma bunius (L.)] wine at different stages of processing. Philippine Science Letters, 6(2):249

Blackman J, Saliba A \& Schmidtke L. 2010. Sweetness acceptance of novices, experienced consumers and winemakers in Hunter Valley Semillon wines. Food Quality and Preference, 21(7):679-683

Buglass AJ. 2011. Handbook of Alcoholic Beverages: technical, analytical and nutritional aspects. John Wiley \& Sons

Busse-Valverde N, Gomez-Plaza E, Lopez-Roca JM , Gil-Muñoz R \& Bautista-Ortin AB. 2011. The extraction of anthocyanins and proanthocyanidins from grapes to wine during fermentative maceration is affected by the enological technique. Journal of Agricultural and Food Chemistry, 59(10):5450-5455

Cheng GW and Crisosto $\mathrm{CH}$. 1995. Browning potential, phenolic composition, and polyphenoloxidase activity of buffer extracts of peach and nectarine skin tissue. Journal of the American Society for Horticultural Science, 120(5):835838

Cimafranca LC. 2017. Physico-chemical properties, phytochemical components, antioxidant and antimicrobial activities of fresh and processed seriales [Flacourtia jangomas (Lour.) Raeusch] fruit (PhD Thesis). University of the Philippines-Los Baños, Laguna

Darias-Martin JJ, Rodriguez O, Diaz E \& Lamuela-Raventos RM. 2000. Effect of skin contact on the antioxidant phenolics in white wine. Food Chemistry, 71(4):483487

Eglinton, McWilliam LS, Fogarty M, Francis L, Kwiatkowsli M, Hoj P \& Henschke P. 2000. The effect of Saccharomyces bayanus - mediated fermentation on the chemical composition and aroma profile of Chardonnay wine. Australian Journal of Grape and Wine Research, 6(3):190-196 
wine production: a preliminary study

Fennema OR. 1996. Food Chemistry. Marcel Dekker, New York

Gomez-Plaza E, Gil-Muñoz R, Lopez Roca JM, Martinez-Cutillas A \& FernandezFernandez JI. 2001. Phenolic compounds and color stability of red wines. Effect of skin maceration time. American Journal of Enology and Viticulture, 52(3):266-270

He F, Liang NN, Mu L, Pan QH, Wang J, Reeves MJ \& Duan CQ. 2012. Anthocyanins and their variation in red wines I. Monomeric anthocyanins and their color expression. Molecules, 17(2):1571-1601

Joshi VK and Sandhu DK. 2000. Influence of ethanol concentration, addition of spices extract, and level of sweetness on physico-chemical characteristics and sensory quality of apple vermouth. Brazilian Archives of Biology and Technology, 43(5):537-545

Kennedy JA and Peyrot Des Gachons C. 2003. Phenolic extraction in red wine production. Practical Winery \& Vineyard, July/August 2003:1-5

Kermasha S, Bathakur NN, Mohan NK \& Arnold NP. 1987. Chemical composition and proposed use of two semi-wild tropical fruits. Food Chemistry, 26(4):253259

King ES, Kievit RL, Curtin C, Swiegers JH, Pretorins IS, Bastian SEP \& Francis IL. 2010. The effect of multiple yeasts co-inoculations on Sauvignon Blanc wine aroma composition. Sensory properties and consumer preference. Food Chemistry, 122(3):618-626

Laleh GH, Frydoonfar H, Heidary R, Jameei R \& Zare S. 2006. The effect of light, temperature, $\mathrm{pH}$ and species on stability of anthocyanin pigments in four Berberis species. Pakistan Journal of Nutrition, 5(1):90-92

Malundo TMM, Shewfelt RL, Ware GO \& Baldwin EA. 2001. Sugars and acids influence flavor properties of mango (Mangifera indica). Journal of American Society for Horticultural Science, 126(1): 115-121

Ough CS. 1992. Wine making basics. Food Product Press. New York

Parvin S, Kader A, Sarkar GC \& Bin Hosain S. 2011. In-vitro study of antibacterial and cytotoxic properties of Flacourtia jangomas. International Journal of Pharmaceutical Sciences and Research, 2(11):2786-2790

Reddy LV and Reddy OVS. 2009. Production, optimization and characterization of wine from mango (Mangifera indica Linn.). Natural Product Radiance, 8(4):426-435

Reynolds AG. 2010. Managing Wine Quality:Viticulture and Wine Quality. Woodhead Publishing Limited, United Kingdom

Ribereau-Gayon P, Dubourdieu D, Doneche B \& Lonvaud A. 2006. Handbook of Enology, The Microbiology of Wine and Vinifications (2nd edn). John Wiley \& Sons Ltd, England

Rossiter KL, Young H, Walker SB, Miller M \& Dawson DM. 2000. The effects of sugars and acids on consumer acceptability of kiwifruit. Journal of Sensory Studies, 15(3):241-250

Schmidt JO and Noble AC. 1983. Investigation of the effect of skin contact time on wine flavor. American Society for Enology and Viticulture, 34:135-138

Sims CA and Morris JR. 1986. Effects of acetaldehyde and tannins on the color and chemical age of red muscadine (Vitis rotundifolia) wine. American Journal of Enology and Viticulture. January 1986. 37:163-165

Singh AK and Singh J. 2010. Evaluation of anti-diabetic potential of leaves and stem of Flacourtia jangomas in streptozotocin-induced diabetic rats. Indian Journal of Pharmacology, 42(5):301 
Sipiora MJ and Granda MJG. 1998. Effects of pre-veraison irrigation cut off and skin contact time on the composition of color and phenolic content of young cabernet sauvignon wines in Spain. American Journal of Enology and Viticulture, 49(2):152-162

Soufleros EG, Pissa I, Petridis D, Lygerakis M, Mermelas K, Boukouvalas G \& Tsimitakis E. 2001. Instrumental analysis of volatile and other compounds of Greek kiwi wine; sensory evaluation and optimization of its composition. Food Chemistry, 75(4):487-500 